\title{
Clinical Study of the Stunned Myocardium
}

\author{
Takahito Sone, M.D., Hideyuki Tsuboi, M.D. \\ and Hiromi Sassa, M.D.
}

\begin{abstract}
Clinical features of 37 cases of stunned myocardium were studied. Mean duration of asynergy was $22.6 \pm 15.7$ days. In all 11 cases of unstable angina without any significant serum creatine kinase leakage, the duration of asynergy was within 14 days. Related coronary lesions were reperfused (spontaneously or by interventional therapy) to TIMI grade II or higher. Transient $\mathrm{Q}$ waves were observed in $39 \%$ of all cases. Negative $\mathrm{T}$ waves tended to be prolonged, and persisted after disappearance of asynergy in $74 \%$ of all cases. ${ }^{201} \mathrm{Tl}$ uptake in the stunned area varied widely between individual cases (ranging from "absent" to "normal"), although it became normal in all cases in the chronic stage. Maldistribution of $99 \mathrm{~m} \mathrm{Tc}$-pyrophosphate (PYP) to the endocardial side of the stunned area was observed in $33 \%$. In 186 cases of acute coronary syndrome, we studied whether or not reversibility of ischemia-disturbed myocardium could be predicted by simultaneous dual isotope SPECT, and found that $201 \mathrm{Tl}$-uptake in the chronic stage significantly improved in the region showing absence of $99 \mathrm{~m} \mathrm{Tc}-$ PYP accumulation or maldistribution of $99 \mathrm{mTc}-\mathrm{PYP}$ to the endocardial side, while reversibility of the region showing transmural ${ }^{99 m}$ Tc-PYP accumulation and a dought pattern was poor. Ischemia-associated myocardial damage recovered to various degrees, and dual isotope SPECT was useful in evaluating the reversibility of such damage already at the acute stage.
\end{abstract}

$\mathbf{R}^{\mathrm{n}}$ EPERFUSED heart shows varying degrees of mechanical stunning (chiefly in the border zone of the infarcted area) depending on the amount of salvaged myocardium. After the famous animal experiment by Braunwald, numerous animal studies on the pathophysiology and etiology of stunned myocardium have been reported? -5

However, available clinical studies are only case presentations, ${ }^{6-8}$ and no comprehensive clinical studies have been carried out. Therefore, we recently conducted a clinical study of stunned myocardium for the following two purposes: (1) to clarify clinical features of stunned myocardium and (2) to assess the ability of dual isotope $\left({ }^{201} \mathrm{TlCl}\right.$ and

Key words:

Stunned myocardium

Dual isotope SPECT

99m Tc-PYP myocardial scintigraphy

${ }^{201} \mathrm{Tl}$ myocardial scintigraphy

Two-dimensional echocardiography
99mTc-PYP) SPECT myocardial imaging to predict the reversibility of ischemia-induced myocardial damage in the early stage after onset of infarction.

\section{SUBJECTS AND METHODS}

The subjects in the first study were 37 patients in whom chronological observation with two-dimensional echocardiography (2DE) disclosed almost complete disappearance of left ventricular wall motion asynergy in the chronic phase and who were rated as having reversible ischemic myocardial damages (RIMD).

Cases of reversible asynergy attributable to causes other than typical coronary insufficiency were excluded from thid study.

The subjects consisted of 29 males and 8

Department of Cardiology, Ogaki Municipal Hospital, Ogaki, Japan

Mailing address: Takahito Sone, M.D., Department of Cardiology, Ogaki Municipal Hospital, Minaminokawacho 4-86, Ogaki 503, Japan 


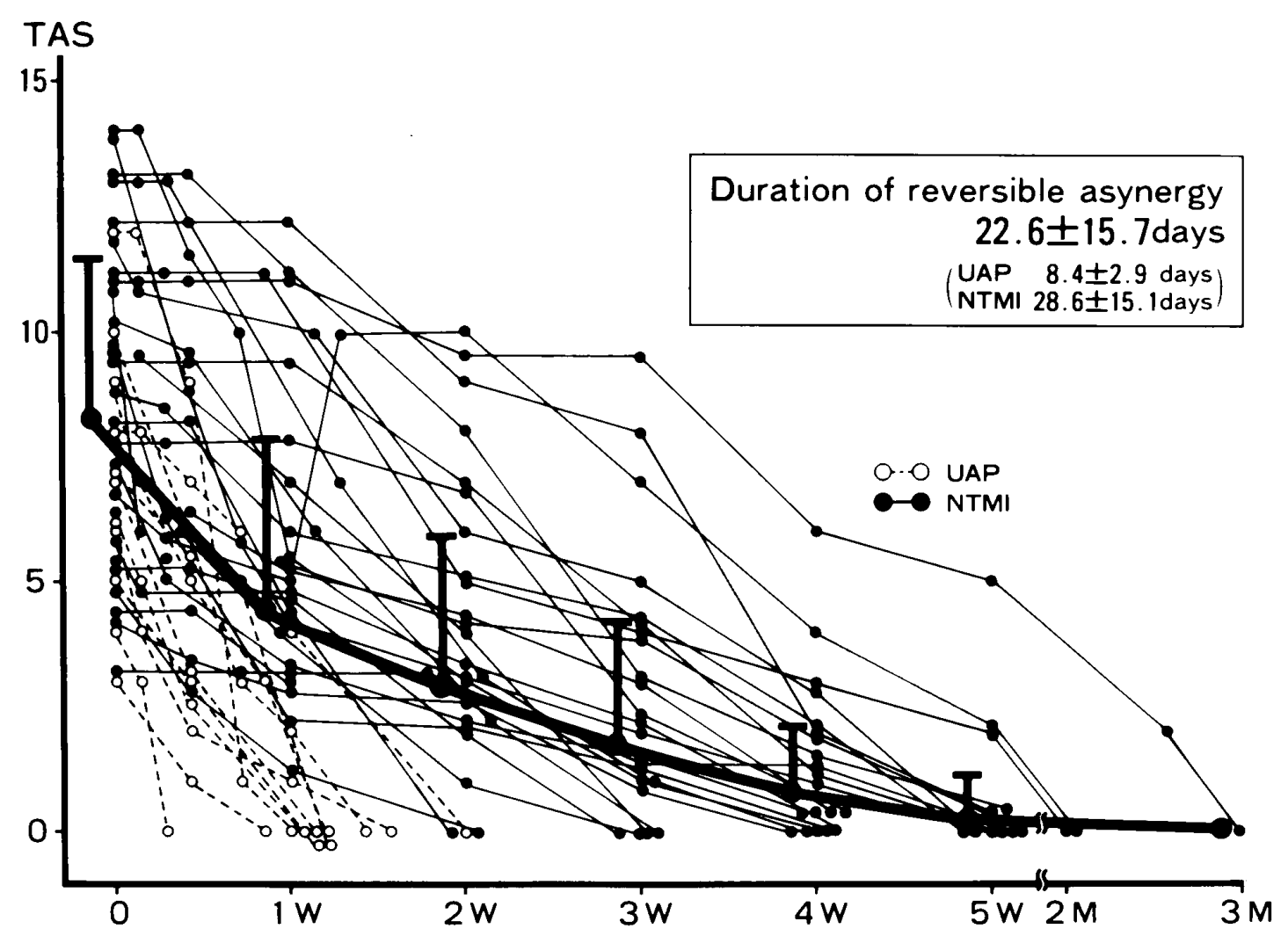

Fig.1. Chronological two-dimensional echocardiographic (2-DE) observation of the course of asynergy in the RIMD group

Open circles indicate cases of unstable angina without significant serum CK leak. Closed circles indicate cases of non-transmural infarction.

TAS: total asynergy score

females, with ages ranging from 38 to 78 years (mean: $62.3 \pm 12.5$ years). Because of the limitation of echo window for 2-DE, the site of ischemia was anteroseptal in the majority of sugjects ( 31 cases) and was inferoposterior in only 6 cases.

The subjects in the second study were 183 patients with acute coronary syndrome in whom dual isotope SPECT image at the acute stage $(2.8 \pm 1.2$ days after onset $)$ could be compared with ${ }^{201} \mathrm{TI}$ SPECT image in the chronic stage (63.1 \pm 18.5 days after onset). Cases in whom infarction occurred again during the observation period were excluded. Assessment of the degree and coverage of wall motion asynergy was performed by $2-\mathrm{DE}$ according to the method described previously, followed by calculation of total asynergy score (TAS) which is a semi-quantitative index of the degree and coverage of asynergy.

SPECT acquisition was performed using simultaneous dual isotope acquisition with the two energy windows set for the $70 \mathrm{KeV}$ photopeak of ${ }^{201} \mathrm{Tl}$ and the $140 \mathrm{KeV}$ photopeak of $99 \mathrm{~m}$ Tc-pyrophosphate (PYP). Projection images acquired on both systems were reconstructed into 2-pixel-thick cardiac short axis tomograms at the same level encompassing the entire heart.

Reconstructed images were processed and displayed using a continuous 255 gray-scale level that corresponds to the percentage count in each segment. The background threshold to the maximal counts in the entire heart was set at $30 \%$ for ${ }^{201} \mathrm{Tl}$ tomograms, $40 \%$ and $60 \%$ for $99 \mathrm{~m}$ Tc-PYP tomograms. The tomographic images were interpreted independently by 2 observers according to the experiences in a series of phantom experiments reported previously! ${ }^{10}$

Overlay images (obtained by overlaying ${ }^{201} \mathrm{Tl}$ on ${ }^{99 \mathrm{~m}} \mathrm{Tc}-\mathrm{PYP}$ tomograms on the same level) were assessed as follows. First, ${ }^{201} \mathrm{Tl}$ uptake was rated with a 3 -grade scale: I (absent), II (reduced) or III (normal). ${ }^{99 \mathrm{~m} T c-}$ PYP accumulation was rated with a 3 -grade scale: A (absent), B (transmural accumula- 
TABLE I TIME COURSE OF ECG IN THE RIMD GROUP (ANALYSIS OF PRECORDIAL LEADS, EXCLUDING V1 LEAD, IN 31 CASES OF ANTEROSEPTAL ISCHEMIA)

\begin{tabular}{|c|c|c|c|c|c|}
\hline \multirow[b]{2}{*}{$E C G$} & \multirow{2}{*}{ Chest pain } & \multirow{2}{*}{$\begin{array}{c}\text { Several hours after } \\
\text { pain relief }\end{array}$} & \multicolumn{2}{|c|}{ Recovery phase of asynergy } & \multirow{2}{*}{$\begin{array}{c}\text { Disapperance of } \\
\text { asynergy }\end{array}$} \\
\hline & & & The first half & The latter half & \\
\hline Abnormal $Q$ & $0 \%$ & $26 \%$ & $39 \%$ & $13 \%$ & $6 \%$ \\
\hline Poor $R$ progression & $18 \%$ & $55 \%$ & $55 \%$ & $55 \%$ & $26 \%$ \\
\hline ST elevation & $100 \%$ & $84 \%$ & $81 \%$ & $74 \%$ & $26 \%$ \\
\hline ST depression & $0 \%$ & $13 \%$ & $13 \%$ & $13 \%$ & $6 \%$ \\
\hline$\dot{T}$ inversion & $0 \%$ & $74 \%$ & $87 \%$ & $100 \%$ & $74 \%$ \\
\hline Deep $T$ inversion & $0 \%$ & $32 \%$ & $13 \%$ & $42 \%$ & $39 \%$ \\
\hline$Q T$ prolongation & $0 \%$ & $26 \%$ & $26 \%$ & $13 \%$ & $0 \%$ \\
\hline Negative $U$ & $0 \%$ & $32 \%$ & $26 \%$ & $0 \%$ & $0 \%$ \\
\hline$n$ & 11 & 31 & 31 & 31 & 31 \\
\hline
\end{tabular}

Numerals indicate the incidence. ST depression, which was judged as representing a reciprocal change, was omitted.

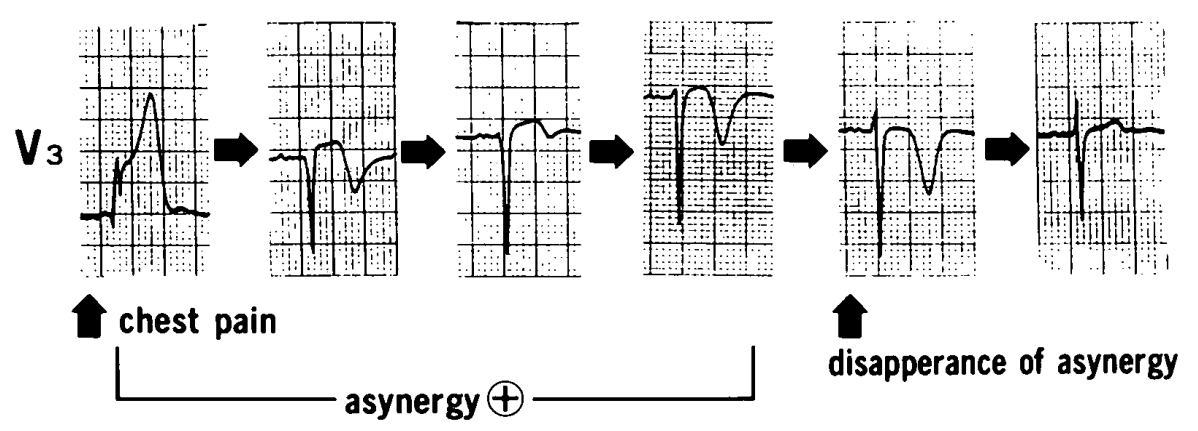

Fig.2. Representative time course of ECG in the RIMD group

tion) or $\mathrm{C}$ (subendocardial accumulation). By combining these two ratings, overlay images were divided into 9 types: (IA through IIIC). For comparison of ${ }^{201} \mathrm{Tl}$ uptake between acute and chronic stages, each short axis tomogram (excluding the apical region) was divided into eight 45-degree segments, and ${ }^{201} \mathrm{Tl}$ uptake in each segment was qualitatively scored: 4 (absent), 3 (severely reduced), 2 (moderately reduced), 1 (slightly reduced) or 0 (normal). Scores for 8 segments were totaled to yield a ${ }^{201} \mathrm{Tl}$ defect score which served as an index of extent and coverage of abnormal ${ }^{201} \mathrm{Tl}$ uptake.

\section{RESULTS}

\section{Clinical features of RIMD}

Serum peak creatine kinase (CK) ranged from 32 to $726 \mathrm{IU}$ (mean: $285 \pm 146 \mathrm{IU}$, normal $<80 \mathrm{IU})$. Eleven patients whose peak $\mathrm{CK}$ level was lower than double the upper normal limit were allocated to the unstable angina pectoris (UAP) group, and 26 patients showing a higher peak $\mathrm{CK}$ were allocated to the non-transmural myocardial infarction (NTMI) group. In coronary angiography of 28 cases in the acute stage, the related coronary lesion was shown as degree 0 in 3 cases, degree $I$ in 4 cases, degree II in 11 cases and degree III in 10 cases according to the TIMI classification: After interventional therapy, the coronary flow was improved to degree II in 2 cases and degree III in 26 cases. Coronary angiography in the chronic stage revealed good patency of related lesion in 31 cases, excluding one case showing good collaterals. Fig. 1 shows the course of asynergy in 37 RIMD cases. In the UAP group, asynergy disappeared within 14 days in all cases. In the NTMI group, asynergy lasted for a longer period (mean: 28.6 days). In 3 cases in which asynergy lasted for 2 months or more, post-infarct 


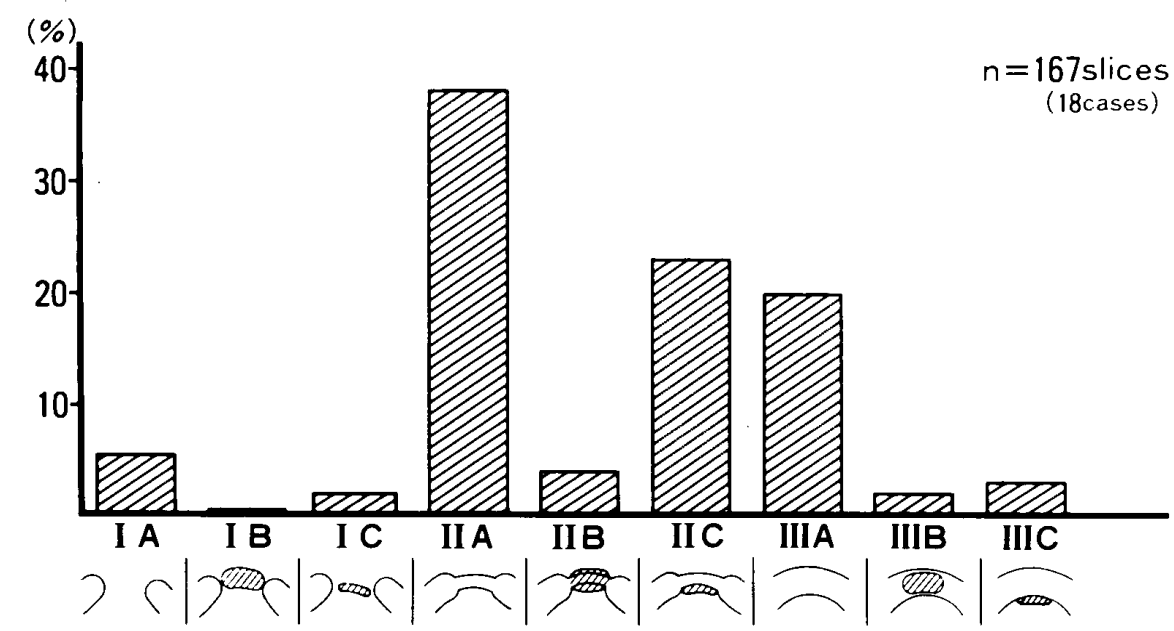

Fig.3. Dual isotope SPECT images for mechanically stunned areas

Overlay images from all tomograms for asynergy-corresponding area in 18 RIMD cases were divided into 9 types according to ${ }^{201} \mathrm{Tl}$ uptake and $99 \mathrm{mTc}-\mathrm{PYP}$ accumulation. Incidences for each type were compared. In schematic presentation of each type (lowest column), dashed area indicates $99 \mathrm{~m}$ Tc-PYP accumulation, and the area surrounded with white line indicates ${ }^{201} \mathrm{Tl}$ uptake.

\section{N.A. 62 y $M$}

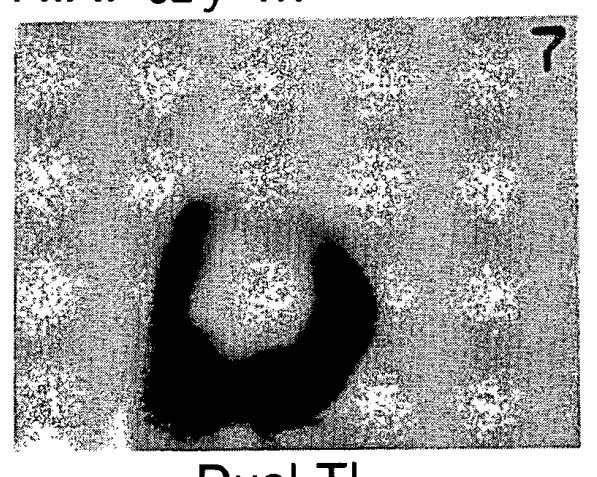

Dual TI

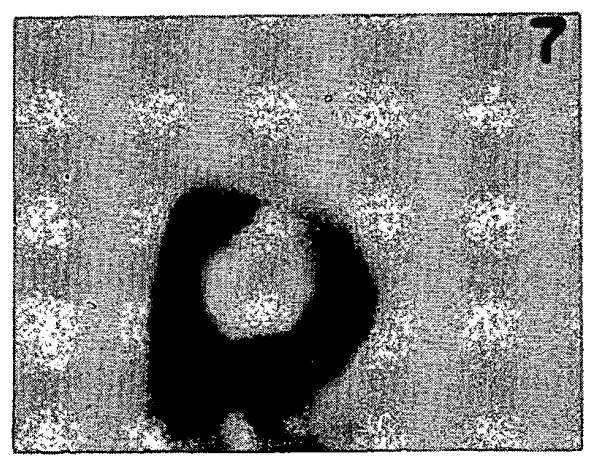

Dual TI+PYP

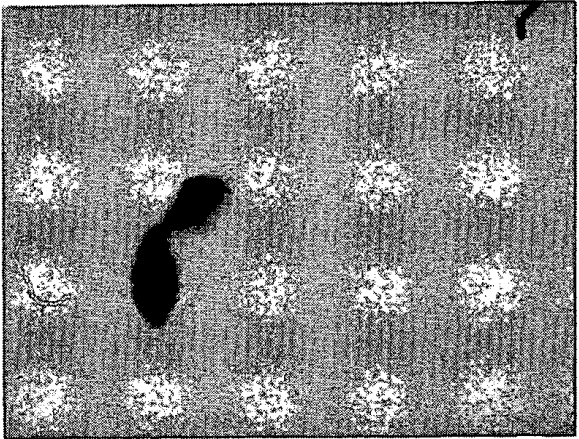

Duai PYP

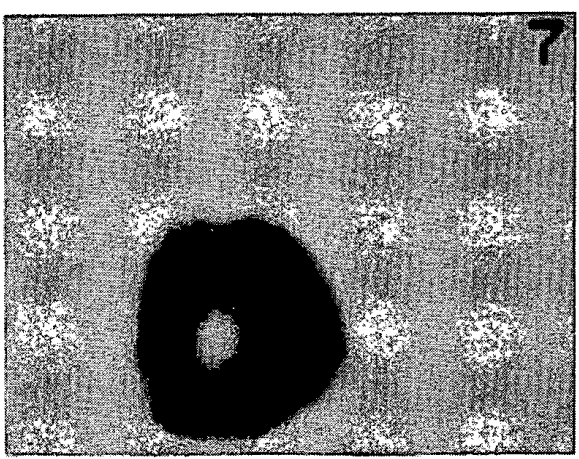

TI restudy

Fig.4. Dual istope SPECT and chronic stage ${ }^{201}$ T1 SPECT images in a patient with anteroseptal infarction in whom early recanalization could be achieved by PTCR.

angina was observed. Mean duration of asynergy for all cases was $22.6 \pm 15.7$ days (range: 2 days to 3 months). As compared to the day of disease onset $(=100 \%)$, total asynergy score grandually decreased with time to $67 \%$ (one week), 35\% (2 weeks), $22 \%$ (3 weeks) and 17\% (4 weeks). Table I compares the time course of standard 12lead ECG data (precordial leads) and the time course of asynergy in 31 cases of an- 


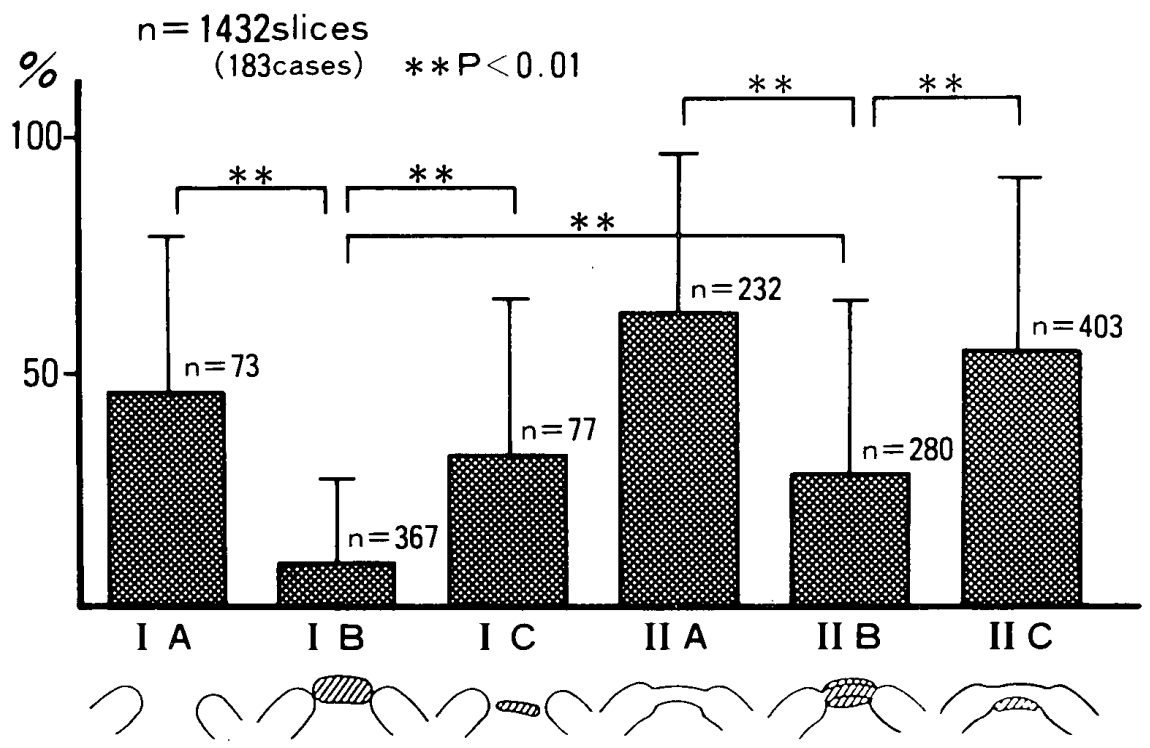

Fig.5. Percent improvement of ${ }^{201} \mathrm{Tl}$ defect score in the chronic stage

Abnormalities of ${ }^{201} \mathrm{Tl}$ uptake., observed in 1432 slices in the acute stage, were classified into the above-mentioned types for comparison of percent improvement of ${ }^{201} \mathrm{Tl}$ defect score in the chronic stage between different types.

teroseptal ischemia. ST elevation was noted in all 11 cases during attack with chest pain. After disappearance of chest pain, more than half of these cases showed poor $\mathrm{R}$ wave progression, ST elevation and $\mathrm{T}$ wave inversion.

Following disappearance of asynergy, poor $\mathrm{R}$ wave progression and $\mathrm{ST}$ elevation were no longer seen. $T$ waves frequently showed biphasic changes, that is, temporary reduction of negative $T$ waves followed by intense inversion. Negative $T$ waves persisted after disappearance of asynergy in $74 \%$ of all cases. In about half of these cases, large negative $\mathrm{T}$ waves (over $1 \mathrm{mV}$ ) were seen. In 16 patients who showed no recurrence of attack during the follow-up period, negative $\mathrm{T}$ waves disappeared $113.3 \pm 75$ days after oneset. Transient $\mathrm{Q}$ waves (referred to as electrical stun) were seen in 12 cases $(39 \%)$. Fig. 2 shows a typical time course of ECG. Dual istope SPECT findings from mechanically stunned myocardium are shown in Fig. 3.

For 18 RIMD cases (5 UAP and 13 NTMI), all tomograms in the asynergy-corresponding area were classified into the above mentioned types, and the incidence of each type was compared.

The most frequent was type IIA (reduced ${ }^{201} \mathrm{Tl}$ uptake and negative ${ }^{99 \mathrm{~m} T c-P Y P}$; 38\%), followed by type IIC (reduced ${ }^{201} \mathrm{Tl}$ uptake and subendocardial $99 \mathrm{mTc}-\mathrm{PYP}$ accumulation; 23\%) and then type IIIA (normal ${ }^{201} \mathrm{Tl}$ uptake and negative ${ }^{99 \mathrm{~m} T \mathrm{~T}-\mathrm{PYP} ; 20 \%) \text {. }}$

Absent ${ }^{201} \mathrm{Tl}$ uptake was seen in $8 \%$ of all tomograms, although ${ }^{201} \mathrm{Tl}$ uptake was normalized in the chronic stage in all cases.

In the UAP group, ${ }^{99 \mathrm{~m} T c-P Y P}$ accumulation was absent in all 5 cases, and ${ }^{201} \mathrm{Tl}$ uptake was abnormal in 3 cases.

2. Reversibility assessment of ischemiacaused myocardial damage in the acute stage

Fig. 4 shows short axis SPECT views of a patient with nontrasmural infarction. ${ }^{201} \mathrm{Tl}$ image (upper left), taken on the third disease day (after early recanalization was achieved by PTCR), showed reduced uptake in a region from the 7 o'clock to 3 o'clock segments. Overlay image (lower left), obtained by overlapping this image with 99mTc-PYP image (upper right), disclosed that the 7-9 o'clock segments were type IIB, 9-12 o'clock segments type IIC and 12-3 o'clock segments type IIA. Tl image in the chronic stage (lower right ) revealed marked improvement of ${ }^{201} \mathrm{Tl}$ uptake (particularly marked in IIA and IIC segments). Main dual isotope SPECT patterns in 1432 tomograms with abnormal ${ }^{201} \mathrm{Tl}$ uptake from 183 cases of acute coronary syndrome without complication by reinfarction were classified into the above-mentioned types, and percent improvement of ${ }^{201} \mathrm{Tl}$ defect score in 


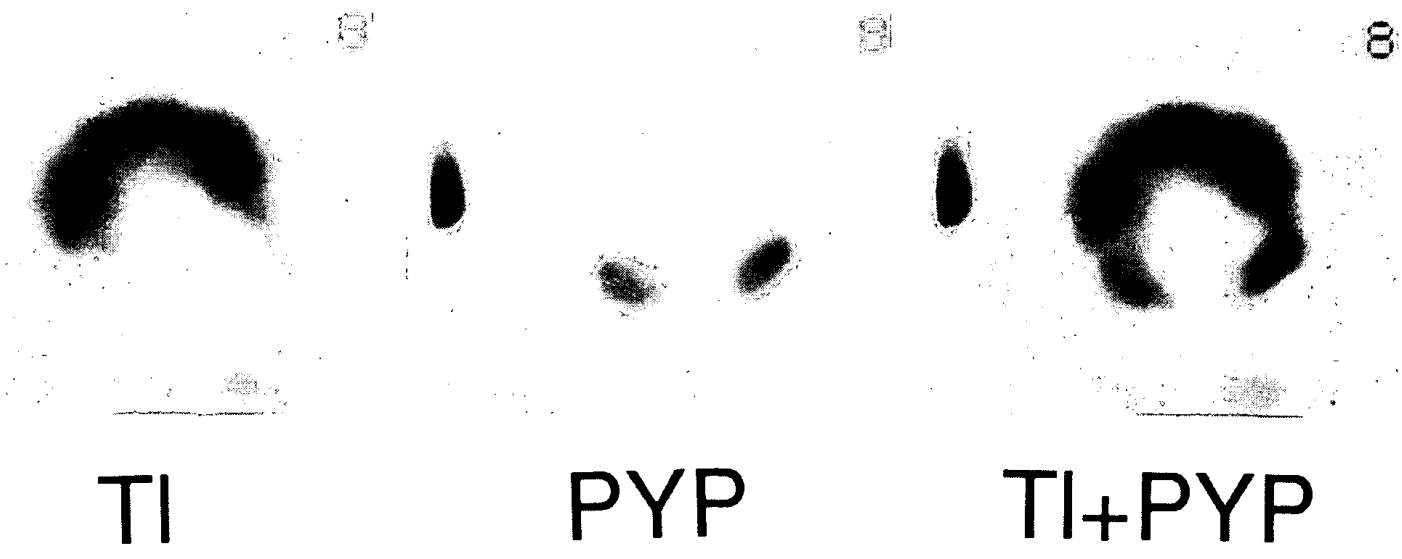

Fig.6. Visualization of doughnut type $99 \mathrm{mTc}$-PYP accumulation by dual isotope SPECT

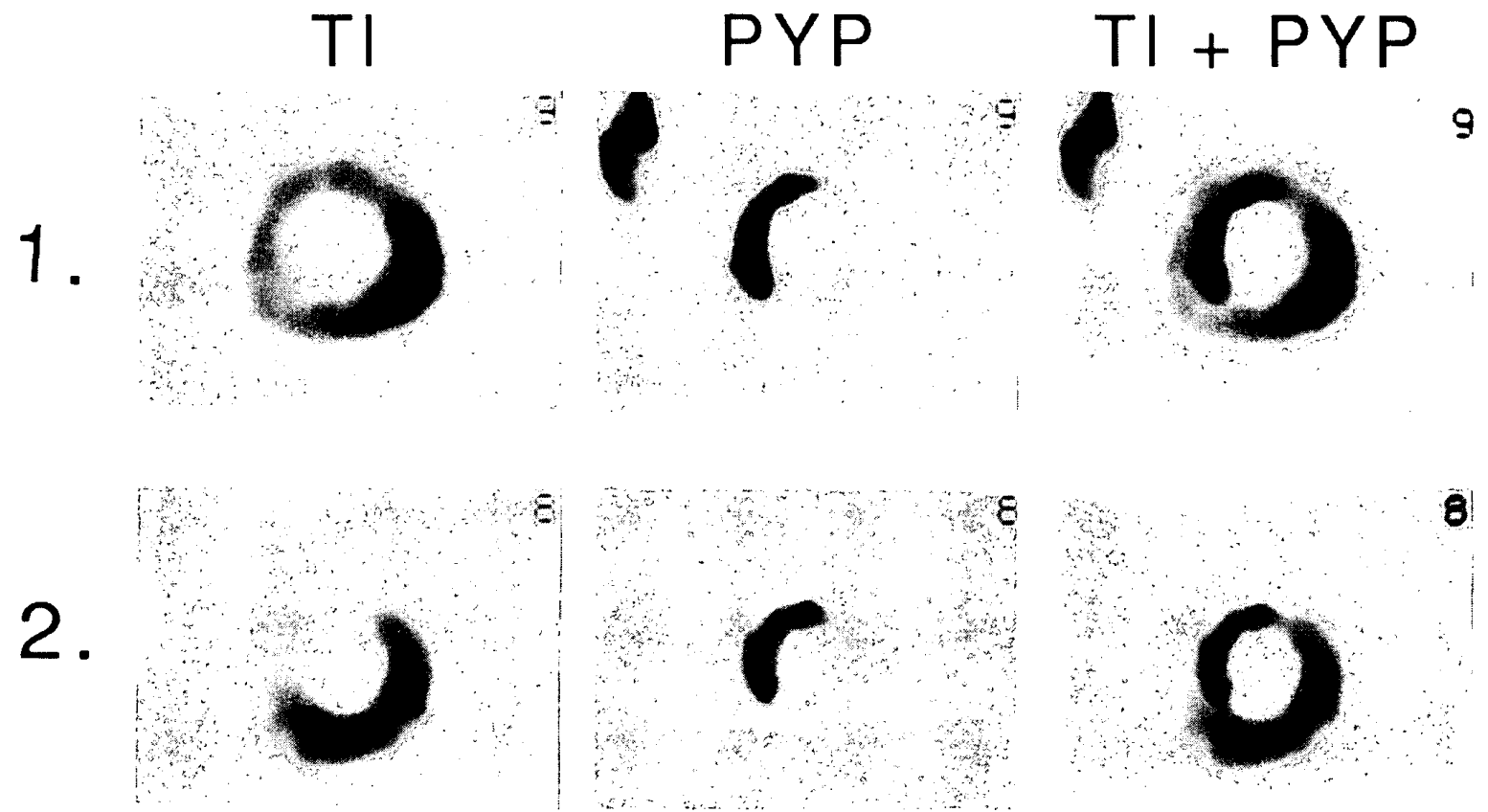

Fig.7. Visualization of wavefront phenomenon on overlay images of dual isotope SPECT

Overlay images in the upper column shows evident maldistribution of ${ }^{99 m}$ Tc-PYP to the endocardial side (a typical feature of type IIC). Tommograms in the lower column indicates further progression of necrosis (type IIC in part of ventricular septum and transmural infarction in most regions).

the chronic stage was compared between different types (Fig. 5). Among type II tomograms (reduced ${ }^{201} \mathrm{Tl}$ uptake), percent improvement of ${ }^{201} \mathrm{Tl}$ defect score was significantly higher in type IIA $(63.9 \pm 35.3 \%)$ and type IIC $(59.6 \pm 37.7 \%)$ as compared to type IIB $(25.7 \pm 35.5 \%)$. This means that reversibility significantly differs between type IIC and IIB even though both show so-called overlap. Among type I tomograms (absent ${ }^{201} \mathrm{Tl}$ uptake), percent improvement was significantly higher in type IA $(46.1 \pm 28.2 \%)$ and IC $(35.4 \pm 21.5 \%)$ as compared to type IB $(9.4 \pm 16.6 \%)$. In detailed observation of type B tomograms, doughnut pattern (markedly lower $99 \mathrm{mTc}$-PYP activity in the central infarcted region as compared to the peripheral region) was seen in 12 cases (Fig. 6 ). This type was frequently seen in cases of extensive infarction where recanalization was not achieved or cases where coronary angiography disclosed no reflow phenomenon even after recanalization. Percent improvement of ${ }^{201} \mathrm{Tl}$ defect score was particu- 
larly poor in the presence of this doughnut pattern $(0.8 \pm 10.2 \%)$.

\section{DISCUSSION}

The course of asynergy in RIMD cases greatly differed between individual cases. One possible cause for this difference is varying degrees of ischemic damage. In RIMD-UAP cases without significant CK leak and $99 \mathrm{~m}$ Tc-PYP accumulation, asynergy disappeared within 2 weeks, while a longer period was required for asynergy to disappear in many cases of RIMD-NTMI presenting with $99 \mathrm{~m}$ Tc-PYP accumulation. $99 \mathrm{~m}$ Tc-PYP accumulation indicates the presence of irreversible necrosis ${ }^{11}$ so the severity of reversible injury in the border zone seems to be maximal. The difference in the severity of damage was also reflected in ${ }^{201} \mathrm{Tl}$ SPECT imases. In the stage of myocardial damage, ${ }^{201} \mathrm{Tl}$ uptake was variable (ranging from "absent" to "normal"). In reperfused myocardium, ${ }^{201} \mathrm{Tl}$ uptake in the acute stage was greatly affected not only by coronary flow but also by anatomical and metabolic factors associated with ${ }^{201} \mathrm{Tl}$ extraction and retention ${ }^{12}$

Therefore, ${ }^{201} \mathrm{Tl}$ uptake in the acute stage is regarded as reflecting the severity of damage or functional status at that time.

Another possible cause for different course of asynergy between individual cases is cumulative effect of ischemic attack ${ }^{13}$ originating from residual coronary stenosis. In 3 cases where 2 months or more were required for asynergy to disappear, post-infarct angina was marked. It is also known well that silent ischemia frequently occurs after infarction ${ }^{4}$ In the present study, PTCA in the acute stage was performed in only 5 cases. Therefore, this is needed in the future to compare the duration of stunning between cases after spontaneous reperfusion or PTCR (frequently presenting with residual coronary stenosis) and PTCA cases.

Overlap of $99 \mathrm{~m}$ Tc-PYP or ${ }^{111} \mathrm{In}$ antimyosin uptake with ${ }^{201} \mathrm{Tl}$ uptake has been reported by several investigators $15-18$

When we analyzed SPECT images in depth, it was found that some cases showed maldistribution of $99 \mathrm{~m}$ Tc-PYP to the endocardial side and other cases showed no such maldistribution. In our previous phan- tom study using a widely used instrument (Toshiba GCA601A, GMS-55U), dual isotope SPECT could visualize subendocardial infarction in which the necrosis did not extent as much as half way through the ventricular wall to the epicardium. Although it involves some problems to directly apply the results of a phantom study to humans, the influence from motion effect seems to be unlikely because a condition akin to akinesis prevails in the ischemic area in the acute stage and because we performed simultaneous acquisition in the present study.

The results of clinical assessment of reversibility also endorse the importance of a judgment as to maldistribution of $99 \mathrm{~m}$ Tc-PYP to the endocardial side in dual isotope SPECT study.

Schofer et al. reported that recovery of regional wall motion was poor in regions showing overlap. We cannot agree with this view for the following reasons: (1) Their study chiefly relied on planar images, (2) Their judgment of asynergy was too early, and (3) They did not distinguish between IIC and IIB types. We think that recovery of asynergy can be expected with a high probability even in overlapped regions (in particular regions showing maldistribution of $99 \mathrm{~m} T \mathrm{c}-\mathrm{PYP}$ to the endocardial side), although the probability is low as compared to the areas showing no accumulation of 99m Tc-PYP.

Some cases had subendocadial necrosis with quite a small depth (unlikely to affect wall motion at least during rest ). We were not surprised with this finding because our previous phantom study had succeeded in imaging a simlar IIC type overlap in a model of $1 \mathrm{~mm}$ subendocardial infarction with $1 \mathrm{~cm}$ ventricular wall thickness.

Usually, myocardial necrosis advances from the endocardial side to the epicardial side $!^{9}$ Even though rough, estimation of the depth of necrosis in the acute stage is essential for determining therapeutic policy (Fig. 7). Although the severity of myocardial damage can be estimated by acute stage ${ }^{201} \mathrm{Tl}$ image alone, reversibility judgment is impossible with it alone. Even when ${ }^{201} \mathrm{Tl}$ uptake is absent in the acute stage, damaged myocardium showing negative $99 \mathrm{mTc}-\mathrm{PYP}$ accumulation or maldistribution of $99 \mathrm{mTc}$ PYP to the endocardial side frequently res- 
tores viability in the chronic stage, indicating the possibility of scintigraphical stunning. On the other hand, cases showing hardly any change in ${ }^{201} \mathrm{Tl}$ uptake in the chronic stage in spite of the presence of type IIC overlap suggest the presence of collaterals (already in the acute stage of infarction) or association with intense residual stenosis, although this assumption requires further study.

Another noteworthy finding from this study was the doughnut pattern of $99 \mathrm{~m}$ TcPYP accumulation?20,21 Although past analyses of planar images appeared to show a pseudo-doughnut pattern formed by the ventricular cavity, the present study demonstrated a true doughnut pattern revealed by animal experiment? 22,23 To our knowledge, visualization of this pattern in the clinical setting has not been achieved before.

SPECT images usually involve blurs caused by technical factors such as motion effect, absorption and partial volume effect. In addition, $99 \mathrm{~m}$ Tc-PYP concentration in the necrotic layer is not uniform, making it difficult to set an appropriate cut-off level for determination of necrosis boundary. Based on our data from basic experiments (using phantoms) and clinical data, we set the cutoff level at $60 \%$ for judgment of the depth of infarction and at $40 \%$ for judgment of the area of infarction.

Based on interpretaion of images with full consideration of these limitations, we conclude that dual isotope SPECT is highly usuful in assessing the features of the myocardium in the acute stage of infarction.

Various ischemic damages which can cause stunned myocardium were found clinically, and the clinical features varied greatly according to the severity of damages. Such diverse clinical features were reflected into varying courses of recovery of asynergy. Analysis of $99 \mathrm{mTc}$-PYP accumulation by dual isotope SPECT provided a useful means for reversibility assessment of myocardial damage.

\section{REFERENCES}

1. BRAUNWALD E, KLONER RA: The stunned myocardium: Prolomged, postischemic ventricular dysfunction. Circulation 1982; 66: 1146

2. ELISS SG, HENSCHKE CI, SANDOR T, WYNNE J, BRAUNWALD E, KLONER RA: Time course of functional and biochemical recovery of myocardium salvaged by reperfusion. J Am Coll Cardiol 1983; 1: 1047

3. MAUSER M, HOFFMEISTER HM, NIENABER C, SCHAPER W: Influence of ribose, adenosine and AICAR on the rate of myocardial adenosine triphoshate synthesis during reperfusion after coronary artery occlusion in the dog. Circ Res 1985; 56: 220

4. HOFFMEISTER HM, MAUSER M, SCHAPER W: Reginal function during accelerated ATP repletion after myocardial ischemia. Circulation 1983; 68: III-193

5. BECKER LC, LEVINE JH, DIPAULA AF, GUARNIERI T, AVERSANO T: Reversal of dysfunction in postischemic stunned myocardium by epinephrine and postextrasytolic potentiation. $J$ Am Coll Cardiol 1986; 7: 580

6. BASHOUR TT, KABBANI SS, BREWSTER HP, WALD SH, HANNA ES, CHENG TO: Transient $Q$ waves and reversible cardiac failure during myocardial ischemic: Electrical and mechanical stunning of the heart. Am Heart J 1983; 106: 780

7. BETEMAN TM, CZER LSC, GRAY RJ, MADDAHI J, RAYMOND MJ, GEFT IL, GANZ W, SHAH PK, BERMAN DS: Transient pathologic $Q$ waves during acute ischemic events: An electtocardiographic correlate of stunned but viable myocardium. Am Heart $J$ 1983; 106: 1421

8. NARAHARA KA, HILLERT MC, Jr SMITHERMAN TC, BURDEN LL: Alterations in left ventricular function during therapy of unstable angina pectoris: Relationship to clinical outcome. Am Heart $J$ 1984; 107: 261

9. SONE T, ISHIDA A, SASSA H, OKUMURA Y, YASUDA E, ENDO T: Reversible ischemic myocardial damage: Clinical observation using two-dimensional echocardiography. J Cardiography 1986; 16: 571

10. SONE T, TSUBOI H, SASSA H, OKUMURA Y: Characterization of asynergic myocardium in acute coronary sydrome using simultaneous dual radionuclide emission computed tomography. $J$ Cardiol 1990; 20: (in press)

11. JANSEN DE, CORBETT Jr, BUJA LM, HANSEN C, UGOLINE V, PARKEY RW, WILLERSON JT: Quantification of myocardial injury produced by temporary coronary artery occlusion and reflow with technetium-99m-pyrophosphate. Circulation 1987; 75: 611

12. MELIN JA, BECKER LC, BULKLEY BH: Differences in thallium-201 uptake in reperfused and nonreperfused myocardial infarction. Circ Res 1983; 53: 414

13. NINOMIYA L, HASHIDA J, GEFT I, CHAUX E, SHELL W, FISHBEIN MC, RITT J, YANO J, GANZ W: Brief repeat episodes of ischemia have a cumulative effect and may cause myocardial necrosis. Am J Cardiol 1981; 47: 445

14. COHN PF: Asymptomatic coronary artery disease: Patholophysiology, diagnosis, management. Mod Concepts Cardiovasc Dis 1981; 50: 55

15. SCHOFER J, MATHEY DG MONTZ R, BLEIFELD W, STRITZKE P: Use of dual intracoronary scintigraphy with thallium-201 and 
techinetium-99m pyrophosphate to predict improvement in left ventricular wall motion immediately after intracoronary thrombolysis in acute myocardial infarction. J Am Coll Cardiol 1983; 2: 737

16. SCHOFER J, SPIELMANN RP, BROMEL T, BLEIFELD W, MATHEY DG: Thallium201/techinetium-99m pyrophosphate overlap in patients with acute myocardial infarction after thrombolysis: Prediction of depressed wall motion despite thallium uptake. Am Heart J 1986; 112: 291

17. HASHIMOTO $\mathrm{T}$, KAMNARA $\mathrm{H}$, FUDO $\mathrm{T}$, TAMAKI S, TAKATSU Y, HATTORI R, TOKUNAGA S, KAWAI T, UOZU K: Significance of technetium-99m/thallium-201 overlap on simultaneous dual emission computed tomography in acute myocardial infarction. Am J Cardiol 1988; 61: 1181

18. JOHNSON LL, SELDIN DW, KELLER AM, WALL RM, BHATIA K, BINGHAM CO, TRESGALLO ME: Dual isotope thallium and Indium antimyosin SPECT imaging to identify acute infarct patients at further ischemic risk. Circulation 1990; 81: 37

19. REIMER KA, JENNINGS RB: The wavefront phenomenon of myocardial ischemic cell death.
Lab Invest 1979; 40: 633

20. BUJA LM, PARKEY RW, STOKELY EM, BONTE FJ, WILLERSON JT: Pathophysiology of technetium-99m stannous pyrophosphate and thallium-201 scintigraphy of acute anterior myocardial infarcts in dogs. $J$ Clin Invest 1976; 57: 1508

21. BUJA LM, PARKEY RW, DEES JH, STOKELY EM, HARRIS RA, BONTE FJ, WILLERSONJT: Morphologic Correlates of tchnetium-99m stannous pyrophosphate imaging of acute myocardial infarcts in dogs. Circulation 1975; 52: 596

22. ZARET BL, DICOLA VC, DONABEDIAN RK, PURI S, WOLFSON S, FREEDMAN GS, COHEN LS: Dual radionuclide study of myocardial infarction: Relationship between myocardial uptake of potassium-43, technetium-99m stannous pyrophosphate, regional myocardial blood flow and creatine phosphokinase depletion. Circulation 1976; 53: 422

23. SOCHOR H, SCHWAIGER $M$, SCHELBERT HR, HUANG SC, ELLISSON D, HANSEN $\mathrm{H}$, SELIN C, PARODI O, PHELPS ME: Relationship between T1-201, Tc-99m (Sn) pyrophosphate and F-18 2-deoxyglucose uptake in ischemically injured dog myocardium. Am Heart $J$ 1987; 114: 1066 